\title{
Legislation and regulation in the era of online sexual health: how do we ensure provision of safe, high-quality care?
}

Authors: Jo Gibbs*, Soazig Clifton, Pam Sonnenberg, Ann Blandford, Anne Johnson, Claudia Estcourt

\section{*Corresponding author Jo Gibbs}

Centre for Population Research in Sexual Health and HIV, Institute for Global Health, Mortimer

Market Centre, off Capper Street, London WC1E 6JB

jo.gibbs@ucl.ac.uk

$\underline{02031082071}$

\section{Affiliations:}

(JG, SC, AJ, PS): Institute for Global Health, University College London, London, UK

(AB): Department of Computer Science, University College London, London, UK

(CE) School of Health \& Life Science, Glasgow Caledonian University, Glasgow, UK

Advances in digital health and novel diagnostics for sexually transmitted infections (STIs) and HIV have created new opportunities for people to access information, testing and, in some cases, treatment remote from traditional healthcare settings.

Legislation and regulation can facilitate or impede innovation in service delivery. For example, the Health and Social Care Act of 2012 moved responsibility for public health, including the majority of sexual health services, from the NHS to local government. Shifts in commissioning and service delivery have occurred, with major disinvestment in sexual health services, which has led to innovative models of care being introduced, including online services [1].

There is an underlying but un-evidenced assumption that online sexual health services will preserve access and increase uptake at a reduced cost. This has led many services to introduce or expand their online presence, which ranges from simple unidirectional health promotion to more ambitious self-sampling services which aim to 'channel shift' those without symptoms away from face-to-face services and into online care.

All healthcare professionals, healthcare services, and the medicines and devices they use are regulated, whether care is 'traditional' or remote, including online. Most regulations were established in the pre-digital era, although many professional bodies in the UK have adapted their existing guidance to incorporate online services. There are three key areas of regulation which are particularly relevant to online care:

(i) Safety of prescribing: In 2013, the General Medical Council (GMC) published pragmatic advice on prescribing for patients who are assessed via remote consultation, including online[2].

(ii) Quality of care: Online services should be registered with the Care Quality Commission (CQC) and are subject to review using the same five criteria as other health and social care services (services should be safe, effective, caring, responsive to people's needs, and well-led).

(iii) Regulation of technology: if an online system involves a level of automation in diagnosis, prevention, monitoring, or treatment, or involves a component that is interpreting a test result, it is classified as an active "medical device" or an in vitro 
diagnostic device, which require registration with the Medicines and Healthcare products Regulatory Agency (MHRA) and CE marking [3].

Despite these clarifications to the guidance, a number of areas of uncertainty remain.

Open access: Legislation requires sexual health services in England to be provided open access, therefore local authorities must provide services to all people living within that area[4] without the need for GP referral. The effect of initial triage only being offered online on people who do not have easy, private access to the internet, or who are unable to navigate this service due to language barriers, mental capacity, or lack of digital literacy is not yet known and requires further monitoring.

Safeguarding: Access to sexual health services does not require proof of identity and services are often used by under-18s. This creates a tension for online services which must balance the need to safeguard potentially-vulnerable patients with maintaining confidentiality and removing barriers to care. The CQC has already raised concerns about identifying those under 18 in a report on one positively-rated online testing service (SH-24)[5].

Remote diagnosis and prescribing: There is preliminary evidence that uncomplicated chlamydia can be managed completely remotely, with provision of results followed by an automated online consultation, and automated prescribing[6]. However, electronic prescriptions may currently only be sent to community pharmacies via the Electronic Prescribing Service (EPS) [7], which requires sharing personal identifiable data including NHS number, not usually collected by sexual health services.

Data Protection and Confidentiality: Following changes to legislation around confidentiality of sexual health services in England, it is now possible for services to use personal identifiers (i.e. NHS numbers), although this is not routine practice[8]. Given the above challenges, there may be advantages of an online service collecting sufficient personal data to allow linkage to NHS number, with consent, to verify age and to allow use of the EPS. However, concerns related to security of online information, how data collected online is being used[9], and fears that people will not access these services if they perceive them to be less confidential, are pertinent.

Internationally, data protection and privacy laws have changed dramatically over the past 20 years, reflecting the developments in digital technology that have occurred over this time, and the need to develop flexible laws that accommodate unforeseen developments in the future[10]. The new European General Data Protection Regulation (GDPR), which was implemented in May 2018, is the most far-reaching and wide-ranging legislation in existence[10]. It strengthens data subjects' rights, requires openness and transparency, and has specific requirements for automated decision making systems[10][11]. For example, Article 22(1) states that "the data subject shall have the right not to be subject to a decision based solely on automated processing, including profiling, which produces legal effects concerning him or her or similarly significantly affects him or her" [11]. If sexual health services move to purely automated online triage systems, then some of the conditions that will need to be in place include provision of information about the processing, and methods for an individual to easily access human intervention or challenge a decision[11].

Other changes to legislative framework: Although published in 2017, the provisions within the medical device regulations and in vitro diagnostic regulations are being implemented over a "transition period" and only come fully into force in 2020 and 2022 respectively[3]. At present, there is uncertainty as to what will happen with such provisions that have not been fully implemented on the date that Brexit occurs[12]. 
The UK is seeing an era of rapid transition of sexual health services in which online service provision is centre stage. While it is now technically feasible to deliver comprehensive online Sexual Health services, much of the shift in delivery has happened before a number of legal and regulatory issues have been elucidated, and adapted where necessary. We need a cohesive, multi-agency approach to addressing these challenges if we are to harness the potential for online sexual health services whilst safeguarding the most vulnerable and remaining true to the founding principles of sexual health care.

1 Robertson R, Wenzel L, Thompson J, et al. Understanding NHS financial pressures. Published Online First:

2017.https://www.kingsfund.org.uk/sites/files/kf/field/field_publication_file/Understanding NHS financial pressures - full report.pdf (accessed 14 Mar 2017).

2 Council GM. Good practice in prescribing and managing medicines and devices. 2013. http://www.gmc-uk.org/Prescribing_guidance_updata.pdf_51250626.pdf

3 MHRA. Medical devices: EU regulations for MDR and IVDR - GOV.UK. 2017.https://www.gov.uk/guidance/medical-devices-eu-regulations-for-mdr-and-ivdr (accessed 26 Mar 2018).

4 HM Government. The Local Authorities ( Public Health Functions and Entry to Premises by Local Healthwatch Representatives ) Regulations 2013/351.

2013;275:16.https://ec.europa.eu/futurium/en/system/files/ged/eidas_regulation.pdf (accessed 1 Mar 2018).

5 Care Quality Commission. SH:24 Inspection report. 2017.www.sh24.org.uk (accessed 1 Mar 2018).

6 Estcourt CS, Gibbs J, Sutcliffe L, et al. The eSexual Health Clinic system for management, prevention, and control of sexually transmitted infections: exploratory studies in people testing for Chlamydia trachomatis. Lancet Public Heal 2017;2:e182-90. doi:10.1016/S24682667(17)30034-8

$7 \quad$ HM Government. The National Health Service Act 2006: The Pharmaceutical and Local Pharmaceutical Services (Prescriptions, Payments and Listings ) Directions 2013. 2013. http://www.legislation.gov.uk/uksi/2013/349/pdfs/uksi_20130349_en.pdf (accessed 1 Mar 2018).

8 Gibbs J, Sonnenberg P, Estcourt CS. Confidentiality of sexual health patients' information what has history taught us and where do we stand? Sex Transm Infect 2017;93:2. doi:10.1136/sextrans-2016-053002

9 Greenfield P. The Cambridge Analytica files: the story so far. Guard. 2018.https://www.theguardian.com/news/2018/mar/26/the-cambridge-analytica-files-thestory-so-far (accessed 10 May 2018).

10 International Comparative Legal Guides. Data Protection 2018. The Rapid Evolution of Data Protection Laws. https://iclg.com/practice-areas/data-protection-laws-and-regulations/therapid-evolution-of-data-protection-laws (accessed 13 Jun 2018).

11 ICO. Guide to the General Data Protection Regulation (GDPR). Published Online First: 2018.https://ico.org.uk/media/for-organisations/guide-to-the-general-data-protectionregulation-gdpr-1-0.pdf (accessed 21 Mar 2018). 
Dennis A. It's all a question of timing: Medical Devices, In Vitro Diagnostic Devices, EU Regulations, and Brexit. Leg. Cerebrum.

2017.http://lifescienceslawblog.fieldfisher.com/2017/its-all-a-question-of-timing-medicaldevices-in-vitro-diagnostic-devices-eu-regulations-and-brexit/ (accessed 26 Mar 2018).

Word count (excluding title page, abstract, references, figures, tables): 1002

The Corresponding Author has the right to grant on behalf of all authors and does grant on behalf of all authors, an exclusive licence (or non exclusive for government employees) on a worldwide basis to the BMJ Publishing Group Ltd to permit this article (if accepted) to be published in STI and any other BMJPGL products and sub-licences such use and exploit all subsidiary rights, as set out in our licence http://group.bmj.com/products/journals/instructions-forauthors/licence-forms

\section{Funding:}

The work included within this article was funded by:

1. The Electronic Self-Testing Instruments for Sexually Transmitted Infection (eSTI ${ }^{2}$ ) Consortium, funded under the UKCRC Translational Infection Research (TIR) Initiative supported by the Medical Research Council (Grant Number G0901608) with contributions to the Grant from the Biotechnology and Biological Sciences Research Council, the National Institute for Health Research on behalf of the Department of Health, the Chief Scientist Office of the Scottish Government Health Directorates, and the Wellcome Trust;

2. An i-sense Partnership Resource Fund, as part of a larger Engineering and Physical Sciences Research Council UK (EPSRC) project (Grant Number EP/K031953/1) 